\title{
Crescimento de Espécies do Gênero Brachiaria, sob Déficit Hídrico, em Casa de Vegetação 1
}

\author{
Jorge Luiz Schirmer de Mattos², José Alberto Gomide ${ }^{3}$, Carlos Alberto Martinez y Huaman ${ }^{4}$
}

\begin{abstract}
RESUMO - Avaliaram-se as características morfogênicas, fisiológicas e produtivas de espécies de Brachiaria, durante e após período de estresse hídrico. Os tratamentos foram arranjados em um esquema fatorial 4 x 5 - quatro espécies de Brachiaria (B. decumbens, $B$. brizantha, $B$. humidicola e $B$. mutica) e cinco níveis de potencial hídrico do solo (-0,01, -0,03, -0,1, -0,5 e -1,5 MPa) - em um delineamento experimental de blocos ao acaso, com três repetições. O experimento foi instalado em casa de vegetação, em colunas de PVC com $40 \mathrm{~cm}$ de altura e $30 \mathrm{~cm}$ de diâmetro. Os déficits hídricos foram impostos durante 23 dias e, após este período, um grupo de plantas foi mantido sob condições normais de disponibilidade de água no solo, durante, aproximadamente, uma semana, para se avaliar a capacidade de recuperação das plantas. A taxa de alongamento das lâminas foliares foi comprometida em $B$. brizantha e a taxa de senescência de lâminas foliares em B. mutica foi aumentada com o decréscimo do potencial hídrico no solo, denotando a maior sensibilidade destas duas espécies ao déficit hídrico. Observou-se controle estomático sobre as trocas gasosas em folhas de todas as espécies. O déficit hídrico reduziu a fotossíntese líquida em todas espécies, mais acentuadamente em B. mutica e B. humidicola. Todas as espécies recuperaram suas atividades fotossintéticas normais após o déficit hídrico, mas apenas a $B$. brizantha restabeleceu o status hídrico de seus tecidos foliares. O déficit hídrico afetou mais acentuadamente a área de lâminas foliares verdes em $B$. brizantha e $B$. decumbens, a produção de matéria verde seca de lâminas foliares em todas as espécies estudadas, e a produção de matéria verde seca de colmos em B. decumbens e B. mutica.
\end{abstract}

Palavras-chave: biomassa, condutância estomática, fotossíntese, potencial hídrico foliar, taxas de aparecimento, alongamento e senescência

\section{Effect of Water Deficit on the Growth of Brachiaria Species in Greenhouse}

\begin{abstract}
This study aimed to evaluate the tolerance of Brachiaria species (B. decumbens, B. brizantha, B. humidicola and $B$. mutica) to low soil water potential. Morphogenetical, physiological and production characteristics were estimated during and after the stress period. The experimental treatments resulted from 4 x 5 factorial arrangement consisting of four Brachiaria species and five soil water potential $(-0,01 ;-0,03 ;-0,1 ;-0,5$ and $-1,5 \mathrm{MPa})$ distributed in randomized block design, with three replications. The experiment was carried out in greenhouse, in PVC column pot $40 \mathrm{~cm}$ high and diameter of $30 \mathrm{~cm}$. The soil water potentials were imposed during 23 days after a regrowth period of 22 days. After the period of stress, soil moisture was maintained at field capacity for one week to evaluate the recovery of the plants. Leaf blade elongation rate in B. brizantha and leaf blade senescence rate in B. mutica varied across soil water potential, suggesting these species to be less tolerant to low soil water potential. Stomatal gas exchange control was observed in all species. Water deficit reduced photosynthesis rate of all species, particularly in B. mutica and B. humidicola. The species recovered their photosynthesis rate after water deficit, but only $B$. brizantha recovered its leaf tissue water potential. Soil water deficit had a detrimental effect on green leaf dry matter production of all species through reduced production of green leaf area mainly in B. brizantha and B. decumbens and reduced culm dry matter production of B. decumbens and B. mutica.
\end{abstract}

Key Words: biomass, leaf appearance, elongation and senescence rates, leaf net photosynthesis, stomatal conductance, water potencial

\section{Introdução}

A deficiência de água no solo interfere nas relações hídricas, na fisiologia e na morfologia das plantas forrageiras a ponto de causar estresse hídrico, que, conforme a magnitude, pode limitar severamente a produção de forragem e até mesmo a sobrevivência da espécie.
O estresse hídrico desenvolve-se na planta quando a taxa de transpiração excede a taxa de absorção e o transporte de água na planta (Berkowitz, 1998). Acredita-se que as raízes atuam como sensores do déficit de água no solo, que é detectado pelas célulasguarda dos estômatos, mesmo antes de qualquer déficit hídrico ser observado nas folhas (Zhang \& Davies, 1990; Salah \& Tadieu, 1997), por meio de

\footnotetext{
${ }_{1}^{1}$ Parte da tese do primeiro autor.

${ }^{2}$ Estudante de doutorado, Departamento Zootecnia, UFV, bolsista do CNPq.

3 Bolsista do CNPq, Departamento de Zootecnia, UFV (jagomide@ufv.br).

${ }^{4}$ Professor de Fisiologia Vegetal da USP, Ribeirão Preto - SP(carlosamh@ffclrp.usp.br).
} 
sinais (ácido abscísico) enviados à parte aérea da planta. A baixa disponibilidade de água no solo acarreta desidratação, redução do crescimento e aceleração da senescência dos tecidos na planta, comprometendo o crescimento por reduzir as taxas de expansão foliar e fotossíntese (Ludlow \& Ng, 1976; Benett \& Sullivan, 1981), as taxas de aparecimento (Ng et al., 1975; Van Loo, 1992) e de senescência (McIvor, 1984) de lâminas foliares, que reduzem a área foliar em espécies gramíneas forrageiras.

A magnitude com que o déficit hídrico afeta o crescimento e a produção, pela redução na área foliar, depende da relação entre a taxa de expansão e o potencial hídrico foliar durante o estresse e a recuperação, após chuva ou irrigação (Ludlow \& Ng, 1977).

As plantas desenvolvem mecanismos de adaptação à seca como: fechamento estomático ( $\mathrm{Ng}$ et al., 1975; Chaves, 1991), ajustamento osmótico (Thomas, 1986; Barker et al., 1993), ajustamento da parede celular (Neumann, 1995), produção de folhas menores (Klar et al., 1978), redução da área foliar (Rosenthal et al., 1987; Chaves, 1991) e aumento na densidade e profundidade de raízes (Doss et al., 1960; Kano et al., 1999). No entanto, o fechamento dos estômatos e a redução da área foliar são mecanismos que limitam a produtividade, uma vez que provocam queda na absorção de $\mathrm{CO}_{2}$ e na interceptação de luz, respectivamente.

Estima-se que, dos 48 milhões de hectares de pastagens cultivadas na região dos cerrados, cerca de $85 \%$ são ocupados com espécies de Brachiaria, principalmente $B$. decumbens $(55 \%)$, B. brizantha (20\%) e B. humidicola (9\%) (Macedo, 1995). Temse aventado que a $B$. decumbens e $B$. brizantha são tolerantes à seca (Soares Filho, 1994). Todavia, pouco se conhece sobre os atributos que conferem tolerância à seca a estas espécies.

Objetivou-se avaliar a tolerância à seca de quatro espécies de Brachiaria - B. decumbens Stapf, B. brizantha (Hochst. ex A. Rich) Stapf cv Marandu, B. humidicola (Rendle) Schweickerdt e B. mutica (Forsk) Stapf - a partir de seus atributos morfogênicos, fisiológicos e produtivos, durante e após déficit hídrico.

\section{Material e Métodos}

Avaliou-se o comportamento de quatro espécies do gênero Brachiaria (B. decumbens cv. Basilisk, $B$. brizantha cv. Marandu, B. humidicola e B. mutica) durante os períodos de déficit hídrico e de recupera- ção do estresse. Em cada um destes períodos, os tratamentos foram arranjados em esquema fatorial $4 \times 5$, ou seja, quatro espécies de Brachiaria e cinco potenciais hídricos do solo (-0,01, -0,03, -0,1, -0,5 e -1,5 MPa). O delineamento experimental foi o de blocos ao acaso, com três repetições para cada período de avaliação.

O experimento foi instalado em casa de vegetação telada lateralmente, na Unidade de Crescimento de Plantas do Departamento de Biologia Vegetal da UFV, Viçosa-MG. As plantas foram cultivadas em colunas de PVC com capacidade de $28,27 \mathrm{dm}^{3}$ ( $40 \mathrm{~cm}$ de altura e $30 \mathrm{~cm}$ de diâmetro) contendo amostras retiradas de um argisolo, às profundidades de 0-20 e $20-40 \mathrm{~cm}$, compostas $(\mathrm{kg} / \mathrm{kg})$ por areia grossa $(0,37)$, areia fina $(0,16)$, silte $(0,06)$ e argila $(0,41)$ e a seguinte composição química: $\mathrm{pH}$ em água $(1: 2,5)=5,3 ; \mathrm{Ca}^{2+}$, $\mathrm{Mg}^{2+} \mathrm{e} \mathrm{Al}^{3+} 1,00,5$ e $0,1 \mathrm{cmol}_{\mathrm{c}} / \mathrm{dm}^{3}, \mathrm{Pe} \mathrm{K} 2,0$ e $40 \mathrm{mg} /$ $\mathrm{dm}^{3}$, respectivamente, e saturação de bases de $36,7 \%$.

$\mathrm{O}$ solo foi destorroado e passado em peneira com malhas de $7 \mathrm{~mm}$ e submetido ao revolvimento, para secagem ao ar, durante 40 dias.

$\mathrm{Na}$ amostra de solo retirada a $0-40 \mathrm{~cm}$ de profundidade, estabeleceu-se a curva característica de retenção de água no solo ( $\hat{Y}=0,156443$ $0,0466138 \log \left|\Psi_{\text {solo }}\right|$ ), em que os valores de (conteúdo de água no solo) compreenderam os níveis de 0,$25 ; 0,22 ; 0,20 ; 0,16$ e $0,15 \mathrm{~kg} / \mathrm{kg}$, equivalentes aos valores de $\Psi_{\text {solo }}$ (potencial hídrico do solo) de -0,01; $-0,03,-0,1 ;-0,5 ;-1,0$ e - $1,5 \mathrm{MPa}$, conforme Richards (1949). A partir dessa curva característica de retenção de água no solo, estimaram-se os valores do $\Psi$ solo aplicados em cada tratamento.

Na amostra de solo coletada a $0-20 \mathrm{~cm}$ de profundidade, transferida para a parte superior dos vasos, foram aplicados $498 \mathrm{mg} / \mathrm{dm}^{3}$ de calcário dolomítico, $3.792 \mathrm{mg} / \mathrm{dm}^{3}$ de superfosfato simples, $321 \mathrm{mg} / \mathrm{dm}^{3} \mathrm{de}$ cloreto de potássio e $111 \mathrm{mg} / \mathrm{dm}^{3}$ de sulfato de amônio.

Dois dias antes da semeadura/plantio, foram adicionados sete litros de água em cada vaso, de modo a elevar a umidade do solo até um valor próximo à capacidade de campo, estimada em $0,25 \mathrm{~kg} / \mathrm{kg}$, condição de umidade do solo equivalente a $-0,01 \mathrm{MPa}$, mantida até o início do período de déficit hídrico.

As quatro gramíneas foram cultivadas, cada uma em 30 vasos, totalizando 120 vasos, de modo que a metade dos vasos foi destinada às avaliações durante o período de déficit hídrico e o restante, para as avaliações realizadas no período de recuperação do estresse. 
A B. decumbens, B. brizantha e B. humidicola foram estabelecidas via sementes e a $B$. mutica, por mudas, com vistas a obter cinco plantas por vaso.

Após a emergência das plântulas, foram aplicados, semanalmente, $139 \mathrm{mg} / \mathrm{dm}^{3}$ de sulfato de amônio em cobertura. $\mathrm{O}$ corte de uniformização foi feito a $15 \mathrm{~cm}$ acima do do solo em $B$. mutica e a $10 \mathrm{~cm}$ nas outras espécies.

Cada nível de umidade do solo foi imposto a um conjunto de 24 vasos, seis de cada espécie, perfazendo um total de 120 vasos. A irrigação dos vasos submetidos ao potencial hídrico de -0,03 a -1,5 MPa foi suspensa até que o respectivo $\Psi$ solo fosse alcançado, o que ocorreu em torno de dois a sete dias após a suspensão da irrigação. Os vasos correspondentes aos tratamentos com $\Psi_{\text {solo }}$ de -0,01 MPa foram irrigados normalmente durante o período de estresse, mantendose a umidade em nível da capacidade de campo.

Os níveis de estresse foram monitorados a partir de duas a três pesagens diárias de $50 \%$ dos vasos (60 vasos), utilizando-se uma balança com precisão de $5 \mathrm{~g}$, realizando-se, nessas ocasiões, a complementação da água, de modo a manter a umidade no nível concernente a cada tratamento. A cada três dias, porém, realizouse a pesagem de todos os vasos, ao final da tarde, de maneira a corrigir eventuais variações no peso dos vasos de um mesmo tratamento.

Em cada rega, a correção da umidade do solo foi feita com base na diferença entre o peso atual do vaso e o peso prefixado para cada tratamento. Assumindo-se que a água da torneira apresentou relação peso/volume de 1:1, a irrigação foi realizada de modo a complementar a água faltante em termos de volume $(\mathrm{mL})$.

$\mathrm{O}$ período de estresse hídrico foi interrompido quando as folhas mais baixas das plantas submetidas a $-1,5 \mathrm{MPa}$ apresentaram sintomas visíveis de murcha.

Ao final do período de estresse hídrico, as plantas da metade dos vasos (60 unidades experimentais), representando as três repetições (blocos), foram cortadas rente ao solo e colhidas para posteriores avaliações. Por sua vez, as plantas da outra metade dos vasos foram irrigadas normalmente, mantendo-se a umidade do solo de todos os vasos próxima à capacidade de campo, por nove dias, com vistas à avaliação da capacidade de recuperação das espécies submetidas ao estresse. No final do período de recuperação, todas as plantas foram submetidas ao corte a $10 \mathrm{~cm}$ do solo e avaliadas.

A temperatura e a umidade relativa do ar foram monitoradas dentro da casa de vegetação, com auxílio de um termohigrógrafo, a partir do corte de uniformização das avaliações até o final do experimento. Os valores médios e respectivos desvios-padrão foram: $29,9 \pm 3,0^{\circ} \mathrm{C}$ e $21,0 \pm 2,6^{\circ} \mathrm{C}$, e $65,8 \pm 6,7$ e $47,2 \pm 10,1 \%$, respectivamente, para temperaturas máximas e mínimas e umidade relativa do ar.

As características morfogênicas foram avaliadas durante os 19 dias do período de estresse, conforme metodologia de Davies (1993).

As características fisiológicas compreenderam medições instantâneas do potencial hídrico de lâminas foliares, com o emprego de uma bomba de pressão (Scholander et al., 1965), da fotossíntese líquida, condutância estomática e transpiração, determinadas com o auxílio de um analisador de gases no infravermelho (IRGA), modelo ADC, LCA-2 (Analytical Development Company, Inglaterra) com câmaras fotossintéticas Parkinson modelo PLC (B), que também forneceram os valores da radiação fotossinteticamente ativa (RFA) $(400-700 \mathrm{~nm})$. As avaliações das características fisiológicas, feitas nas lâminas de folhas recém-expandidas, foram realizadas sempre no mesmo horário solar, ao longo do período experimental: de $4 \mathrm{~h}$ às $6 \mathrm{~h}$ (antemanhã) efetuaram-se as leituras com a bomba de pressão e, de 9 às 11 h30, as avaliações com o IRGA.

O potencial hídrico das lâminas foliares foi medido imediatamente após a retirada de uma lâmina foliar de cada unidade experimental, seccionada na região da lígula. As determinações com o IRGA envolveram cinco leituras de uma mesma lâmina foliar por vaso (cinco unidades observacionais), perfazendo 20 unidades experimentais por dia (equivalente a um bloco).

Para determinação da produção de biomassa, as plantas foram colhidas ao final do período de estresse e separadas em parte aérea verde (lâminas e colmos + bainhas + inflorescências, quando presentes), parte aérea senescente (partes senescentes de lâminas foliares) e sistema radicular, a fim de se determinar o peso da matéria fresca destas frações.

A área de lâmina foliar verde foi medida em um sistema de análise de imagens (AREA METTER DT, Delta $T$ Devices Ltda, Inglaterra). Amostras representativas das porções referentes à parte aérea foram secas a $70^{\circ} \mathrm{C}$, em estufa com ventilação forçada, até atingirem peso constante.

A recuperação do sistema radicular foi feita somente em amostras dos vasos submetidos aos $\Psi_{\text {solo }}$ 
de - $0,01,-0,1$ e - 1,5 Mpa, obtidas pelo uso de um trado tipo caneca com $50 \mathrm{~mm}$ de diâmetro, com o qual foram retiradas duas amostras por vaso, à profundidade de 0-40 cm - uma localizada no centro e a outra próxima à borda da unidade experimental. Estas amostras foram imediatamente colocadas sobre um jogo de peneiras com malhas decrescentes até $2 \mathrm{~mm}$, onde receberam jatos de água de torneira, a fim de se separar o solo das raízes. Concluído o processo de recuperação das raízes, juntou-se o material proveniente das duas amostras, formando-se uma amostra composta, que foi colocada em estufa com ventilação forçada a $70^{\circ} \mathrm{C}$, por 72 horas, para se obter o peso da matéria seca desta fração.

A partir do peso da matéria seca das raízes das amostras compostas, retiradas de um volume conhecido de solo $\left(1,57 \mathrm{dm}^{3}\right)$, estimou-se o peso da matéria seca do sistema radicular por vaso.

Ao final do período de recuperação, foram avaliadas as características fisiológicas (potencial hídrico de lâminas foliares, fotossíntese líquida, condutância estomática e transpiração), conforme procedimentos já descritos.

A análise de variância dos dados, realizada separadamente para cada um dos períodos de estresse hídrico e de recuperação, considerou as fontes de variação: bloco, espécie, $\Psi_{\text {solo }}$, espécie x $\Psi_{\text {solo }}$ e erro experimental. Utilizou-se o módulo do potencial hídrico do solo $\left|\Psi_{\text {solo }}\right|$ e do potencial hídrico de lâminas foliares $\left|Y_{1}\right|$, para o ajuste dos modelos matemáticos mais adequados aos dados experimentais.

Aplicou-se o teste Tukey a 5\% de significância para as médias das características avaliadas em resposta ao fator qualitativo (espécie), enquanto aquelas em resposta ao fator quantitativo (potencial hídrico do solo), foram ajustadas equações de regressão. Escolheu-se a equação de melhor ajuste aos dados experimentais com base no coeficiente de determinação, na significância da regressão e na não-significância $(\mathrm{P}>0,05)$ da falta de ajustamento testado pelo teste $\mathrm{F}$, na significância dos coeficientes de regressão testados pelo teste T de Student, a 1\% (**) e 5\% (*) de probabilidade, e na natureza biológica da característica em estudo.

Os dados de fotossíntese líquida, condutância estomática e transpiração foram corrigidos, por regra de três simples, empregando-se os valores médios da radiação fotossinteticamente ativa. Os valores da fotossíntese líquida, condutância estomática e transpiração são médias de cinco medições (unidades observacionais) realizadas em três unidades experimentais e de três avaliações no tempo (45 observações). Os valores do potencial hídrico das lâminas foliares representam as médias de nove observações (medições em três unidades experimentais e três avaliações no tempo). Realizaram-se testes para se estimarem correlações lineares, em nível de até 5\% de probabilidade, envolvendo as seguintes características: potencial hídrico de lâminas foliares x condutância estomática, fotossíntese líquida x condutância estomática e transpiração x condutância estomática, matéria verde seca de lâminas foliares $\mathrm{x}$ potencial hídrico de lâminas foliares, matéria verde seca de colmos x potencial hídrico de lâminas foliares e relação lâmina/colmo x potencial hídrico de lâminas foliares.

\section{Resultados e Discussão}

A B. mutica apresentou taxa de aparecimento de lâminas foliares mais alta $(\mathrm{P}<0,05)$ que as demais espécies, que não diferiram entre si (Tabela 1). Observou-se tendência de queda da taxa de aparecimento de lâminas foliares com o $\Psi$ solo.

A taxa de alongamento de lâminas foliares (Figura 1) de $B$. brizantha decresceu com $\Psi_{\text {solo }}$ segundo a equação: $\hat{\mathrm{Y}}=43,85-5,31^{\mathrm{m}} \log \left(\Psi_{\text {solo }}\right), \mathrm{R}^{2}=0,74$. Para as demais espécies, observou-se a mesma tendência, sem, entretanto, alcançar nível de significância ( $\mathrm{P}>0,05)$ com valores médios de 44,9; 14,9 e 5,2 mm/ dia/perfilho, para B. mutica, B. decumbens e $B$. humidicola, respectivamente; ou seja, as duas ùltimas espécies apresentaram menores taxas de alongamento foliar $(\mathrm{P}<0,05)$.

A taxa de senescência de lâminas foliares aumentou $(\mathrm{P}<0,05)$ com decréscimo do $\Psi_{\text {solo }}$ em B. mutica,

Tabela 1 - Taxa de aparecimento de lâminas foliares (TApL) em espécies de Brachiaria (período de estresse)

Table 1 - Leaf appearence rate (LAR) in Brachiaria species in the stress period

\begin{tabular}{lc}
\hline $\begin{array}{l}\text { Espécie } \\
\text { Specie }\end{array}$ & $\begin{array}{c}\text { TApL }(\mathrm{mm} / \text { dia.perfilho }) \\
\text { LAR }(\mathrm{mm} / \text { day.tiller })\end{array}$ \\
\hline B. brizantha & $0,09 \mathrm{~b}$ \\
B. decumbens & $0,08 \mathrm{~b}$ \\
B. humidicola & $0,07 \mathrm{~b}$ \\
B. mutica & $0,26 \mathrm{a}$ \\
\hline
\end{tabular}

$a>b(P<0,05)$. 
segundo a equação: $\hat{\mathrm{Y}}=0,032+243,903 \Psi_{\text {solo }}-$ $557,28 \mathrm{Y}^{2}+267 \mathrm{Y}^{3} ; \mathrm{R}^{2}=0,99$. As espécies B.humidicola, B. decumbens e B. brizantha, que se mostraram insensíveis ao potencial hídrico do solo, apresentaram médias de 6,$64 ; 4,97$ e $3,25 \mathrm{~mm} / \mathrm{dia} /$ perfilho, respectivamente. Entretanto, apenas tendência de aumento foi observada em $B$. decumbens e B. humidicola. Por outro lado, as espécies não diferiram $(\mathrm{P}>0,05)$ em termos de taxa de senescência de lâminas foliares.

As diferenças morfogênicas observadas evidenciam a mais intensa dinâmica de fluxo de tecidos em $B$ mutica, em razão de suas altas taxas de de aparecimento, alongamento e senescência foliares.

Vale enfatizar o pequeno efeito do déficit hídrico sobre as características morfogênicas. Estes resultados são surpreendentes, uma vez que os processos de aparecimento, alongamento e senescência de folhas, na maioria das espécies, são geralmente afetados pela baixa disponibilidade de água no solo. A nãosignificância para efeito de estresse hídrico sobre as características morfogênicas da maioria das espécies é atribuída ao pequeno número de repetições e ao nível de significância usado.

O potencial hídrico das lâminas foliares $\left|\Psi_{1}\right|$ das espécies de Brachiaria diminuiu com o decréscimo do potencial hídrico do solo (Figura 2). O potencial hídrico foliar $\left|\Psi_{1}\right|$, sob condição de ponto de murcha, foi reduzido oito vezes em $B$. mutica e de aproximadamente quatro vezes nas demais espécies, relativa-

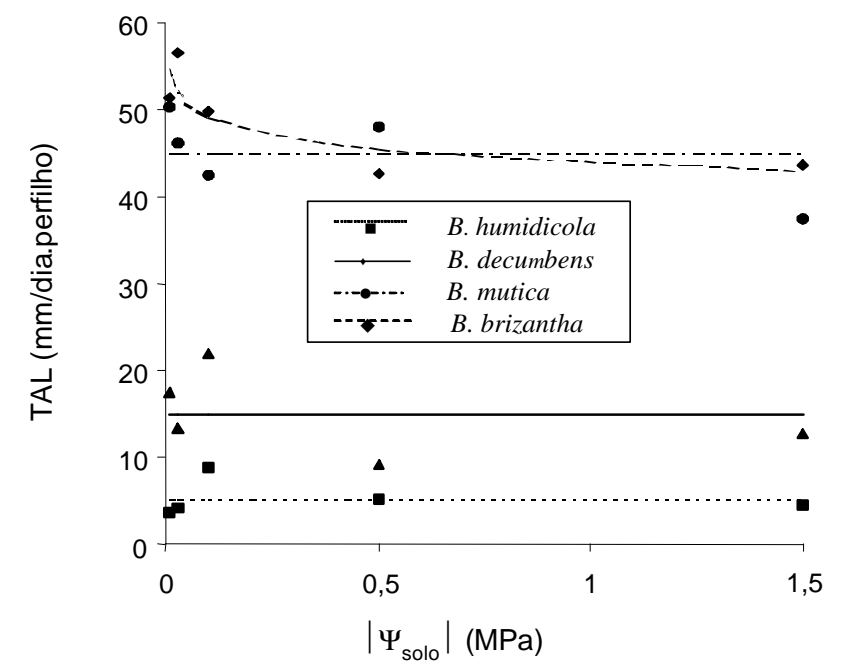

Figura 1 - Taxa de alongamento de lâminas foliares (TAL) das espécies de Brachiaria, em função do potencial hídrico do solo.

Figure 1 - Leaf blade elongation rate (LBER) in Brachiaria species, as a function of the soil water potential. mente ao potencial hídrico do solo de $-0,01 \mathrm{MPa}$. Todavia, apenas sob a condição de ponto de murcha permanente $\left(\Psi_{\text {solo }}\right.$ de $\left.-1,5 \mathrm{Mpa}\right)$, houve diferença entre as espécies, quando a B. mutica apresentou $\left|\Psi_{1}\right|$ inferior aos das outras três espécies.

Também a condutância estomática de B. mutica, $B$. decumbens e B. humidicola variou diretamente com o potencial hídrico do solo, mas a intensidade desse efeito variou conforme a espécie (Figura 3). A B. mutica, embora apresentando o mais alto valor de condutância estomática $\left(0,28 \mathrm{ml} / \mathrm{m}^{2} / \mathrm{s}\right)$, sob condição de capacidade de campo, atingiu valor tão baixo $\left(0,15 \mathrm{ml} / \mathrm{m}^{2} / \mathrm{s}\right)$ quanto ao das outras espécies sob os mais baixos $\Psi_{\text {solo }}$.

Os valores de fotossíntese líquida, sob condição de capacidade de campo, variaram entre 15,0 e $11,0 \mathrm{mmol} / \mathrm{m}^{2} / \mathrm{s}$, respectivamente em B. mutica e B. humidicola. Diferença entre as espécies quanto às suas fotossínteses líquidas foram observadas apenas sob condição de ponto de murcha permanente, em que a $B$. humidicola apresentou o mais baixo valor $\left(5,96 \mathrm{mmol} / \mathrm{m}^{2} / \mathrm{s}\right)$ relativamente à $B$. mutica, cujo valor foi de $11 \mathrm{mmol} / \mathrm{m}^{2} / \mathrm{s}$ (Figura 4 ).

Enquanto a fotossíntese líquida da B.humidicola decresceu linearmente com o $\Psi_{\text {solo, aquelas das }}$ demais espécies apenas foram ligeiramente comprometidas pelos potenciais hídricos do solo compreendidos entre a capacidade de campo e -0,01 MPa, permanecendo insensíveis sob condições de menores valores de $\Psi_{\text {solo }}$.

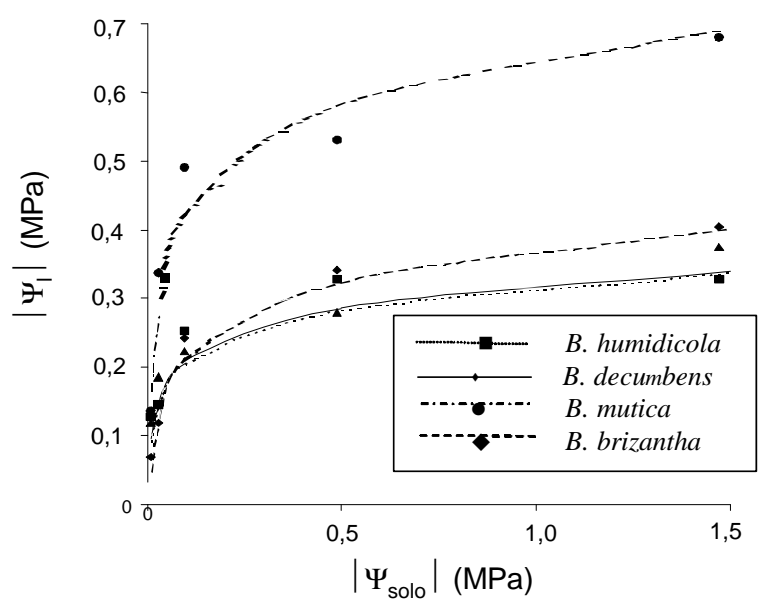

Figura 2 - Potencial hídrico de lâminas foliares $\left|\Psi_{\mid}\right|$das espécies de Brachiaria, em função do potencial hídrico do solo.

Figure 2 - Leaf blade water potential $\mid \Psi_{\text {| }}$ of Brachiaria species, as a function of the soil water potential. 
Diferença de transpiração foliar entre as espécies só foi observada sob condição de $\Psi_{\text {solo }}$ de $-0,05 \mathrm{MPa}$, em que a $B$. humidicola apresentou maior $(\mathrm{P}<0,05)$ valor $\left(6,0 \mathrm{mmol} / \mathrm{m}^{2} / \mathrm{s}\right)$ que a $B$. brizantha $\left(3,8 \mathrm{mmol} / \mathrm{m}^{2} / \mathrm{s}\right)$.

As braquiárias $B$. decumbens e $B$. brizantha não responderam ao potencial hídrico do solo, em termos de transpiração foliar, apresentando média de $4,0 \mathrm{mmol} / \mathrm{m}^{2} / \mathrm{s}$.

O efeito negativo do déficit hídrico sobre as características fisiológicas, verificado no presente estudo corrobora os resultados de vários experimentos envolvendo diferentes espécies de gramíneas, metodologias e condições de cultivo (Doley \& Trivett, 1974; Ng et al., 1975; Ludlow \& Ng, 1976; Buldgen \& François, 1998).

Assim, o comportamento estomático exerceu controle efetivo sobre as trocas gasosas, uma vez que a fotossíntese líquida e a transpiração se correlacionaram linear e positivamente com a condutância estomática (Tabela 2).

Considerando o fato de que a recuperação completa do estresse, em termos fisiológicos, não tenha ocorrido, é possível inferir que as espécies de Brachiaria estudadas, ao restabelecerem suas atividades fotossintéticas normais, foram hábeis em tolerar a falta de água no solo. Estreita relação da fotossíntese líquida

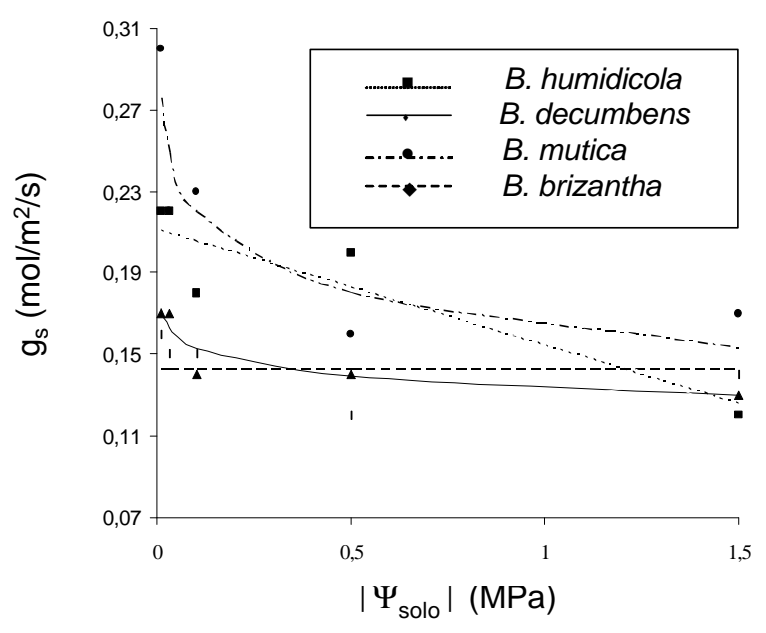

Figura 3 - Condutância estomática $\left(g_{s}\right)$ das espécies de Brachiaria, em função do potencial hídrico do solo.

Figure 3 - Stomatal conductance $\left(g_{s}\right)$ of the Brachiaria species, as a function of the soil water potential ( $\left.\Psi_{\text {soil }}\right)$. com a condutância estomática em Panicum maximum foi relatada por Brown \& Simmons (1979).

Entre as espécies de Brachiaria estudadas, B. humidicola foi a espécie fisiologicamente mais sensível ao déficit hídrico.

Após reidratação, diferença entre as espécies só foi observada nas plantas anteriormente submetidas ao estresse hídrico de ponto de murcha. O potencial hídrico dessas plantas, após nove dias de reidratação sob condição de campo, apresentou grande variação entre as quatro espécies estudadas, desde a completa restauração $(0,08 \mathrm{MPa})$ em $B$. brizantha até a parcial recuperação $(0,30 \mathrm{MPa})$ em $B$. mutica.

Infere-se, assim, que o período de recuperação foi insuficiente para a retomada completa do status hídrico das lâminas foliares em B. mutica, B. decumbens e $B$. humidicola, fato que poderia estar ligado aos componentes do $\Psi_{1}$, provavelmente, ao potencial osmótico (Ford \& Wilson, 1981; Thomas, 1991).

As quatro espécies estudadas se mostraram insensíveis aos níveis de potencial hídrico do solo e não diferiram entre si quanto ao valor de condutância estomática e transpiração, após o período de reidratação. Entretanto, em B. brizantha, foi observado efeito residual do déficit hídrico sobre a transpiração das folhas, o que surpreende, uma vez

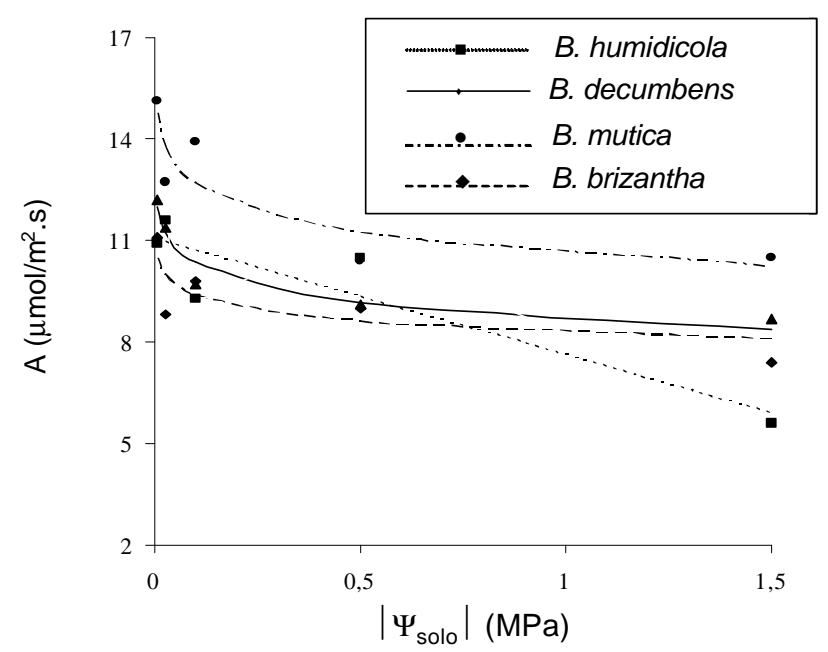

Figura 4 - Fotossíntese líquida das espécies de Brachiaria estudadas, em função do potencial hídrico do solo.

Figure 4 - Net photosynthesis of the Brachiaria species, as a function of soil water potential ( $\left.\Psi_{\text {soil }}\right)$. 
Tabela 2 - Correlações lineares entre condutância estomática $\left(g_{s}\right)$ e fotossíntese líquida $(A)$, transpiração (E) e potencial hídrico de lâminas foliares $\left(\Psi_{1}\right)$, em espécies de Brachiaria (período de estresse)

Table 2 - Linear correlatios between stomatal conductancy $\left(g_{s}\right)$ with net photosynthesis $(A)$, transpiration $(E)$ and leaf blade hidric potencial $\left(\Psi_{1}\right)$, in the stress period

\begin{tabular}{llcc}
\hline $\begin{array}{l}\text { Espécie } \\
\begin{array}{l}\text { Specie } \\
\text { B. decumbens }\end{array}\end{array}$ & $\mathrm{g}_{\mathrm{S}} \times \mathrm{A}$ & $\mathrm{g}_{\mathrm{s}} \times \mathrm{E}$ & $\mathrm{g}_{\mathrm{s}} \times \Psi_{1}$ \\
& \multicolumn{3}{c}{$\begin{array}{c}\text { Coeficiente de correlação } \\
\text { Correlation coefficient }\end{array}$} \\
\hline $\begin{array}{l}\text { B. brizantha } \\
\text { B. humidicola }\end{array}$ & 0,93 & 0,64 & 0,60 \\
B. mutica & 0,79 & 0,85 & - \\
\hline
\end{tabular}

${ }^{1}$ Probabilidade $<0,05$.

${ }^{1}$ Probability $<.05$.

que esta espécie se mostrou insensível ao baixo potencial hídrico do solo no período de estresse.

Segundo Mansfield \& Davies (1985), algumas espécies podem apresentar "efeito residual" do déficit hídrico por vários dias após reidratação dos tecidos foliares, o que pode, inclusive, limitar a absorção de $\mathrm{CO}_{2}$.

Não se detectou "efeito residual" do $\Psi$ solo sobre a fotossíntese líquida $\left(8,25 \mathrm{mmol} / \mathrm{m}^{2} . \mathrm{s}\right)$, tampouco as espécies diferiram entre si $(\mathrm{P}>0,05)$. Esse fato sugere que as espécies de Brachiaria recuperaram suas atividades fotossintéticas normais, ao contrário de alguns resultados relatados na literatura em que a recuperação foi incompleta (Ludlow \& $\mathrm{Ng}, 1976$ ) ou se caracterizou por um "efeito compensatório" (Páez \& Gonzalez, 1995b).

Observou-se alta correlação da condutância estomática com a fotossíntese líquida e a transpiração em todas as espécies de Brachiaria (Tabela 3).

Por outro lado, a correlação entre a condutância estomática e o $\Psi_{1}$ nas espécies de Brachiaria foi fraca. Nem sempre a condutância estomática responde estreitamente ao $\Psi_{1}$, podendo ocorrer mudanças nesta relação ao longo do dia, fenômeno denominado ajustamento dos estômatos (Muchow et al., 1980). Outros fatores podem interferir na correlação da condução estomática, como diferenças de idade da folha para a variação entre espécies, níveis de $\Psi_{\text {solo }}$ e capacidade recuperação do déficit hídrico (Doley \& Trivett, 1974; Ludlow \& Ng, 1974).

A área de lâminas foliares verdes decresceu com a redução da disponibilidade de água no solo em B. brizantha $\left\{\hat{\mathrm{Y}}=0,77-0,19^{\circ} \log \left(\Psi_{\text {solo }}\right) ; \mathrm{R}^{2}=0,65\right\}$ e B. decumbens $\left\{\hat{\mathrm{Y}}=0,52-0,19^{\circ} \log \left(\Psi_{\text {solo }}\right)\right.$; $\left.\mathrm{R}^{2}=0,86\right\}$, tendendo a estabilizar-se em direção aos níveis mais baixos de $\Psi_{\text {solo }}(\mathrm{P}<0,05)$. Para a $B$. mutica e a $B$. humidicola, verificou-se a mesma tendência, sem alcançar significância $(\mathrm{P}>0,05)$, com valores médios de 0,49 e $0,31 \mathrm{~m}^{2} /$ vaso, respectivamente.

A diminuição da área de lâmina foliar verde refletiria o efeito do déficit hídrico sobre as taxas de alongamento e senescência foliares, observações também realizadas por Baruch (1994) e Páez et al., (1995a).

As espécies de Brachiaria diferiram $(\mathrm{P}<0,05)$ quanto à área de lâmina foliar verde apenas nos níveis mais altos de $\Psi_{\text {solo }}$, condições em que a $B$. brizantha sobressaiu-se apenas em relação à $B$. humidicola. Embora não tenha ocorrido diferença $(\mathrm{P}>0,05)$ entre B. decumbens, B. mutica e B. humidicola, o tamanho do aparelho assimilatório da $B$. decumbens tendeu a ser maior que o das outras duas, sob os níveis mais altos de $\Psi_{\text {solo. }}$.

A produção de matéria verde seca de lâminas foliares diminuiu linearmente, $\hat{Y}=25,08-4,09^{\circ} \Psi$ solo, com o potencial hídrico do solo, independentemente da espécie de Brachiaria. Esse decréscimo foi em torno de $26 \%$, comparando-se os valores obtidos sob capacidade de campo (-0,01 MPa) e ponto de murcha permanente (-1,5 $\mathrm{MPa})$. Substancial diferença $(\mathrm{P}<0,05)$ foi observada entre as espécies quanto à produção de matéria verde seca de lâminas foliares (Tabela 4).

Observou-se resposta linear decrescente da produção de matéria verde seca de colmos, em $B$. decumbens $\left(\hat{\mathrm{Y}}=64,83-16,38^{* *} \Psi_{\text {solo }} ; \mathrm{R}^{2}=0,99\right)$ e B. mutica

Tabela 3 -Correlações lineares da condutância estomática $\left(g_{s}\right)$ com fotossíntese líquida $(A)$ e transpiração (E) em espécies de Brachiaria no período de recuperação

Table 3 - Linear correlations between stomatal conductancy $\left(g_{S}\right)$ with net photosynthesis $(A)$ and transpiration $(E)$ in Brachiaria species during the recovery period

\begin{tabular}{lcc}
\hline $\begin{array}{l}\text { Espécie } \\
\text { Specie }\end{array}$ & $\mathrm{g}_{\mathrm{s}} \times \mathrm{A}$ & $\mathrm{g}_{\mathrm{s}} \times \mathrm{A}$ \\
& $\begin{array}{c}\text { Coeficiente de correlação } \\
\text { Correlation }^{1}\end{array}$ \\
\hline B. decuefficient & \\
B. brizantha & 0,71 & 0,87 \\
B. humidicola & 0,87 & 0,91 \\
B. mutica & 0,56 & 0,86 \\
& 0,84 & 0,75
\end{tabular}

${ }^{1}$ Probabilidade $<0,05$.

${ }^{1}$ Probability $<.05$. 
( $\hat{\mathrm{Y}}=47,12-9,97^{*} \Psi_{\text {solo }} ; \mathrm{R}^{2}=0,86$ ), em função do potencial hídrico do solo $(\mathrm{P}<0,05)$. B. brizantha e $B$. humidicola mostraram-se insensíveis ao potencial hídrico do solo; seus valores médios de biomassa de colmo foram $\mathrm{Y}=33,5$ e 24,4 g/vaso, respectivamente.

As espécies diferiram $(\mathrm{P}<0,05)$ apenas em termos de produção de matéria verde seca de colmos sob potencial hídrico do solo de -0,01 e - $0,1 \mathrm{MPa}$, condições em que a $B$. decumbens superou apenas a B. humidicola.

A variação nos níveis de $\Psi_{\text {solo }}$ de - 0,01 para -1,5 $\mathrm{MPa}$ acarretou sensível redução na produção de matéria verde seca de colmos em $B$. decumbens e B. mutica, em torno de 38 e $32 \%$, respectivamente.

Enquanto a matéria seca do sistema radicular diminuiu $(\mathrm{P}<0,05)$ linearmente com o $\Psi$ solo em B. decumbens $\left(\hat{\mathrm{Y}}=38,79-14,03^{\circ} \Psi_{\text {solo }} ; \mathrm{R}^{2}=0,99\right)$, as demais espécies mostraram-se insensíveis, apresentando valores médios de 37,7; 26,5 e 10,5 g/vaso, em $B$. brizantha, B. mutica e $B$. humidicola, respectivamente. Possivelmente, a maior concentração do sistema radicular da $B$. decumbens nas camadas mais superficiais do solo (Corrêa et al., 1999) tenha tornado esta espécie mais suscetível ao estresse hídrico.

Efeitos negativos do déficit hídrico sobre o sistema radicular também foram observados em espécies forrageiras de clima tropical (Baruch, 1994), o que seria resultante do declínio na assimilação líquida, ocasionado pelo decréscimo no potencial hídrico das folhas, associado ao fato de que, nestas condições, a fotossíntese diminui mais rapidamente que a respiração (Pande \& Singh, 1981). Neste estudo, o déficit hídrico provocou significativa queda tanto do potencial hídrico como na fotossíntese líquida das folhas de B. decumbens.

Tabela 4 - Matéria verde seca de lâminas foliares (MVSL) em espécies de Brachiaria no período de estresse

Table 4 - Green leaf blade drymatter (GLBDM) of Brachiaria species in stress period

\begin{tabular}{lc}
\hline Espécie & MVSL $(\mathrm{g} / \mathrm{vaso})$ \\
Specie & GLBDM $($ g/pot $)$ \\
\hline B. brizantha & $39,7 \mathrm{a}$ \\
B. decumbens & $28,5 \mathrm{a}$ \\
B. humidicola & $12,8 \mathrm{~b}$ \\
B. mutica & $16,4 \mathrm{~b}$
\end{tabular}

$\mathrm{a}>\mathrm{b}(\mathrm{P}<0,05)$.

\section{Conclusões}

A $B$. brizantha foi a espécie de maior tolerância ao déficit hídrico, em decorrência da menor sensibilidade de seus estômatos ao estresse, do menor comprometimento de suas taxas de fotossíntese e transpiração, das mais altas taxas de alongamento, das baixas taxas de senescência de suas lâminas foliares e de sua expressiva produção de raízes.

\section{Literatura Citada}

BARKER, D.J.; SULLIVAN, C.Y.; MOSER, L.E. Water deficit effects on osmotic potential, cell wall elasticity, and proline in five forage grasses. Crop Science, v.85, n.2, p.270-275. 1993.

BARUCH, Z. Responses to drought and flooding in tropical forage grasses.I. Biomass allocation, leaf growth and mineral nutrients. Plant and Soil, v.164, n.1, p.87-96, 1994.

BENNETT, J.M.; SULLIVAN, C.Y. Effect of water stress preconditioning on net photosynthetic rate of grain Sorghum. Photosynthetica, v.15, n.3, p.330-337, 1981

BERKOWITZ, G.A. Water and salt stress. In: RAGHAVENDRA, A.S. (Ed.). Photosynthesis: comprehensive treatise. Cambridge: Cambridge University, 1998. p.226-237.

BROWN, R.H.; SIMMONS, R.E. Photossynthesis of grass species differing in $\mathrm{CO}_{2}$ fixation pathways. I. Water-use efficiency. Crop Science, v.19, n.3, p.375-379, 1979.

BULDGEN, A.; FRANÇOIS, J. Physiological reactions to imposed water deficit by Andropogon gayanus cv. bisquamulatus and Cenchrus ciliaris cv. biloela in mixed fodder crop. Journal of Agricultural Science, v.131, n.1, p.31-38, 1998.

CHAVES, M.M. Effects of water deficits on carbon assimilation. Journal of Experimental Botany, v.42, n.234, p.1-16, 1991.

CORREAA, M.R.; KANNO, T.; MACEDO, M.C.M.et al. Produção de raízes em cinco forrageiras tropicais sob pastejo na região dos Cerrados In: REUNIÃO DA SOCIEDADE BRASILEIRA DE ZOOTECNIA, 36., 1999, Porto Alegre. Anais... Porto Alegre : Sociedade Brasileira de Zootecnia, 1999. p.73.

DAVIES, A. Tissue turnover in the sward. In: DAVIES, A. et al. (Eds.) Sward measurement handbook. 2.ed. Hurley: BGS: 1993. p.183-215.

DOLEY, A.; TRIVETT, N.B.A. Effect of low water potentials on transpiration and photosynthesis in mitchell grass (Astrebla lappacea). Australian Journal of Plant Physiology, v.1, n.4, p.539-550, 1974.

DOSS, B.D.; ASHLEY, D.A; BENNETT, O.L. Effect of soil moisture regime on root distribution of warm season forage species. Agronomy Journal, v.52, n.10, p.569-572, 1960.

FORD, C.; WILSON, J.R. Changes in levels of solutes during osmotic adjustment to water stress in leaves of four tropical pasture species. Australian Journal of Plant Physiology, v.8, n.1, p.77-91, 1981.

KANO, T.; UOZUMI, S.; MACEDO, M.C.M.et al. Avaliação de quatro espécies de Brachiaria submetidas ao estresse hídrico. In: REUNIÃO ANUAL DA SOCIEDADE BRASILEIRA DE ZOOTECNIA, 36., Porto Alegre, 1999. Anais... Porto Alegre: Sociedade Brasileira de Zootecnia, 1999. p.79. 
KLAR, A.E.; USBRTI JR.; A., HENDERSON, D.W. Diferencial responses of guinea grass populations to drought stress. Crop Science, v.18, n.5, p.853-857, 1978.

LUDLOW, M.M.; NG, T.T. Effect of water deficit on carbon dioxide exchange and leaf elongation rate of Panicum maximum var. trichoglume. Australian Journal of Plant Physiology, v.3, n.3, p.401-413, 1976.

LUDLOW, M.M.; NG, T.T. Leaf elongation rate in Panicum maximum var. trichoglume following removal of water stress. Australian Journal of Plant Physiology, v.4, n.2, 263-272, 1977.

LUDLOW, M.M.; NG, T.T. Water stress suspends leaf ageing. Plant Science Letters, v.3, n.4, p.235-240, 1974.

MACEDO, M.C.M. Pastagens no ecossistema dos Cerrados: Pesquisa para o desenvolvimento sustentável. In: SIMPÓSIO SOBRE PASTAGENS NOS ECOSSISTEMAS BRASILEIROS, 1., 1995, Brasília. Anais... Brasília: Sociedade Brasileira de Zootecnia, 1995. p.28-62.

MANSFIELD, T.A.; DAVIES, W.J. Mechanisms for leaf control of gas exchange. Bioscience, v.35, n.3, p.158-164, 1985.

McIVOR, J.G. Leaf growth and senescence in Urochloa mosambicensis and $U$. oligotricha in a seasonally dry tropical environment. Australian Journal Agriculture Research, v.35, p.177-187, 1984.

MUCHOW, R.C.; FISCHER, M.J.; LUDLOW,M.M.et al. Stomatal behaviour of kenaf and sorghum in a semiarid tropical environment. II. During the day. Australian Journal of Plant Physiology, v.7, n.5, p.621-628, 1980.

NEUMANN, P.M. The role of wall adjustment in plant resistance to water deficits. Crop Science, v.35, n.5, p.1258-1266, 1995.

NG, T.T.; WILSON, J.R.; LUDLOW, M.M. Influence of water stress on water relations and growth of a tropical $\left(\mathrm{C}_{4}\right)$ grass, Panicum maximum var. trichoglume. Australian Journal of Plant Physiology, v.2, n.4, p.581-595, 1975.

PÁEZ, A.O.; GONZÁLEZ, M.E.; YRAUSQUÍN, X. et al. Water stress and clipping management effects of guineagrass. I. Growth and biomass allocation. Agronomy Journal, v.87, n.4, p.698-706, 1995a.

PÁEZ, A.O.; GONZÁLEZ, M.E. Water stress and clipping management effects of guineagrass: II. Photosynthesis and water relations. Agronomy Journal, v.87, n.4, p.706-711, $1995 b$.
PANDE, H.; SINGH, J.S. Comparative biomass and water status of four range grasses grown under two soil water conditions. Journal of Range Management, v.34, n.6, p.480-484, 1981.

RICHARDS, L.A. Metods of measuring soil moisture tension. Soil Science, v.68, n.1, p.95-112, 1949.

ROSENTHAL, W.D.; ARKIN, G.F.; SHOUSE, P.J.et al. Water deficit effects on tanspiration and leaf growth. Agronomy Journal, v.79, n.6, p.1019-1026, 1987.

SALAH, H.B.H.; TARDIEU, F. Control of leaf expansion rate of droughted maize plants under flutuating evaporative demand. Plant Physiology, v.114, n.3, p.893-900, 1997.

SCHOLANDER, P.F.; HAMMEL, H.T.; BRADSTREET, E.D.et al. Sap pressure in vascular plants. Science, v.148, n.3668, p.339-346, 1965.

SOARES FILHO, C.V. Recomendações de espécies e variedades de Brachiaria para diferentes condições. In: SIMPÓSIO SOBRE MANEJO DE PASTAGEM, 11., 1994, Piracicaba. Anais... Piracicaba: Fundação de Estudos Agrários Luiz de Queiroz, 1994. p.25-48.

THOMAS, H. Acumulation and consumption of solutes in swards of Lolium perenne during drought and after rewatering. The New Phytologist, v.118, n.1, p.35-48, 1991.

THOMAS, H. Effect of rate of dehydration on leaf water status and osmotic adjustment in Dactilis glomerata L., Lolium perenne L. e Lolium multiflorum Lam. Annals of Botany, v.57, n.2, p.225-235, 1986.

VAN LOO, E.N. Tillering, leag expansion and growth of plants of two cultivar s of perennial ryegrass grown using hydroponics at two water potential. Annals of Botany, v.70, n.6, p.511518. 1992.

ZHANG, J.; DAVIES, W.J. Changes in concentration of ABA in the xylem sap as a function of changing soil water status can account for changes in leaf conductance and growth. Plant and Cell Environment, v.13, n.2, p.271-285, 1990. 